\title{
First Implementation of Transfusion Consent Policy in Oman \\ Audit of compliance from a tertiary care university hospital
}

"Arwa Z. Al-Riyami, ${ }^{1}$ Naif Al-Ghafri, ${ }^{2}$ Fehmida Zia, ${ }^{1}$ Mohammed Al-Huneini, ${ }^{1}$ Abdul-Hakeem Al-Rawas, Salam Al-Kindi, ${ }^{4}$ Sachin Jose, ${ }^{5}$ Murtadha Al-Khabori, ${ }^{1}$ Hilal Al-Sabti, ${ }^{6}$ Shahina Daar ${ }^{4}$

$$
\begin{aligned}
& \text { أول تنفيذ لسياسة الموافقة المسبقة لعملية نقل الدم في عُمان } \\
& \text { دراسة تدقيقة على مدى الإلتزام في مستشفى جامعي للرعاية الثلاثية }
\end{aligned}
$$

$$
\text { أروى الريامية، نايف الغافري، فهميدة ضياء، محمد الحنيني، عبد-الحكيم الرواس، سلام الكندي، ساشين خوسيه، }
$$

ABSTRACT: Objectives: Transfusions are a common medical intervention. Discussion of the benefits, risks and alternatives with the patient is mandated by many legislations prior to planned transfusions. At the Sultan Qaboos University Hospital (SQUH), Muscat, Oman, a written transfusion consent policy was introduced in March 2014. This was the first time such a policy was implemented in Oman. This study therefore aimed to assess adherence to this policy among different specialties within SQUH. Methods: The medical records of patients who underwent elective transfusions between June and August 2014 were reviewed to assess the presence of transfusion consent forms. If present, the consent forms were examined for completeness of patient, physician and witness information. Results: In total, the records of 446 transfused patients (299 adult and 147 paediatric patients) were assessed. Haematology patients accounted for $50 \%$ of adult patients and $71 \%$ of paediatric patients. Consent was obtained for $75 \%$ of adult and $91 \%$ of paediatric patients. The highest adherence rate was observed among adult and paediatric haematology specialists (95\% and 97\%, respectively). Consent forms were correctly filled out with all details provided for $51 \%$ and $52 \%$ of adult and paediatric patients, respectively. Among inadequately completed forms, the most common error was a lack of witness details (20-25\%). Conclusion: In most cases, the pre-transfusion consent policy was successfully adhered to at SQUH. However, further work is required to ensure full compliance with the consent procedure within different specialties. Implementation of transfusion consent in other hospitals in the country is recommended.

Keywords: Blood Transfusion; Informed Consent; Policy Compliance; Clinical Audit; Oman.

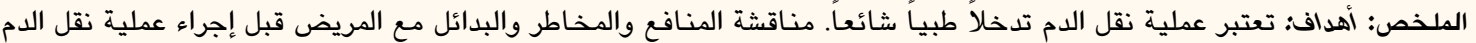

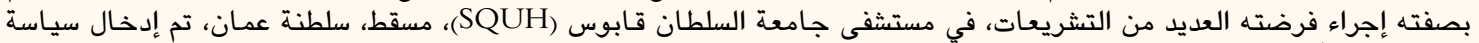

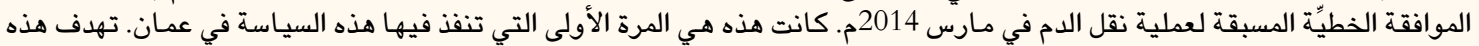

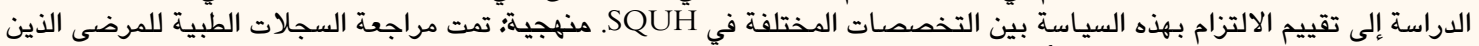

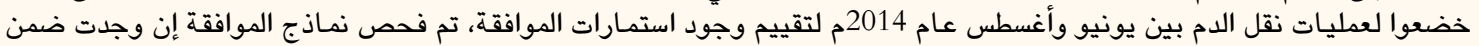

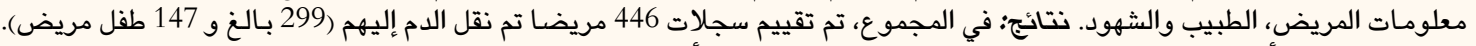

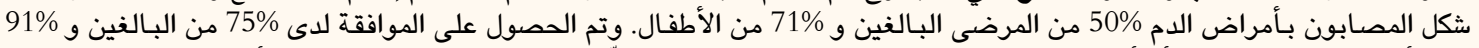

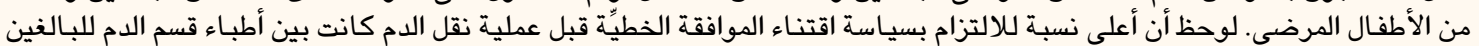

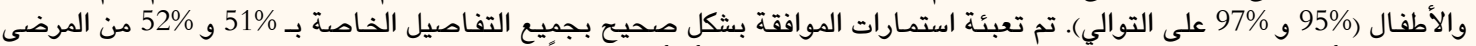

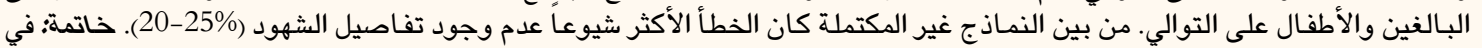

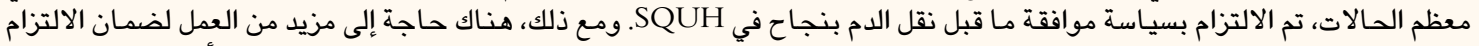

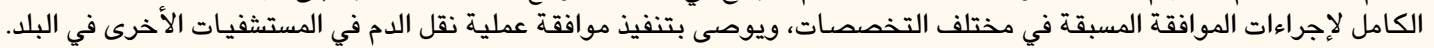

$$
\text { كلمات مفتاحية: نقل الدم؛ موافقة مسبقة؛ الامتثال للسياسات؛ المراجعة السريرية؛ عمان. }
$$

\section{ADVANCES IN KNOWLEDGE}

This study assessed adherence to transfusion consent policy at the Sultan Qaboos University Hospital, the first centre in Oman to implement transfusion consent.

\section{Application to Patient Care}

Written patient consent and discussion of the risks and benefits of transfusion procedures has become increasingly important.

The authors of this study advocate wide implementation of transfusion consent in all hospitals in Oman as an integral part of patient autonomy. 
$\mathrm{B}$ LOOD TRANSFUSION IS A FREQUENT INTERvention which should only be performed to avoid significant morbidity or mortality if not given. ${ }^{1}$ Although blood transfusions are safe in comparison to other medical and surgical interventions, they nevertheless carry certain risks, such as transfusion reactions, alloimmunisation, immunomodulation and transfusion-transmitted infections. ${ }^{2}$ Patient consent for blood transfusions is a topic that has long stimulated debate among healthcare practitioners. ${ }^{2,3}$ Previously, verbal informed consent for a blood transfusion was often considered sufficient to authorise the procedure; however, with the recognition of transfusion hazards, effective and documented counselling of risks and benefits has become increasingly important., ${ }^{2,3}$ As such, patients receiving blood transfusions should be provided with sufficient information regarding the purpose, anticipated benefits, alternatives to the blood transfusion and their expected outcome without the transfusion. Additionally, patients should be made aware of frequent and significant transfusion-related risks. ${ }^{4}$ Following this, the caregiver must obtain patient consent which must be given voluntarily by the patient or a parent or legally appointed guardian, when applicable. ${ }^{5,6}$ Ideally, there should be witnessed verification of the patient's signature. ${ }^{6}$

Worldwide variation exists regarding the practice of obtaining informed consent from patients prior to a blood transfusion. While in many countries this practice is not routine, it is mandated in others, with the prescribing physician being responsible for obtaining consent..$^{6-9}$ Concerns regarding transfusiontransmitted infections have resulted in legislation in some jurisdictions in the USA which requires physicians to obtain written informed consent for blood transfusions. ${ }^{10}$ In the UK, there is a widespread recommendation that patients must be informed about blood transfusions, although this is not routinely practiced., In Canada, requirements to inform patients about blood transfusions are stated in Justice Krever's recommendation for the blood system. ${ }^{8,12}$ This recommendation mandates that patients should be informed about the benefits, risks and alternatives to allogeneic blood transfusions and that this discussion needs to be documented in patients' medical records. ${ }^{12}$

Transfusion consent in Oman was first introduced at the Sultan Qaboos University Hospital (SQUH), Muscat, Oman, in March 2014. The transfusion consent policy mandates that all patients-or their eligible guardians in paediatric cases or with adult patients unable to give informed consent-provide pre-transfusion written consent by signing a consent form which confirms that they have been given information on transfusion of blood and/or blood components by a qualified physician. The physician must explain the risks and benefits of and alternatives to blood transfusion prior to obtaining the consent. The consent process should be witnessed by another healthcare provider, such as a physician or a nurse, and all information, including any refusal of blood and blood components, should be documented in the patient's electronic medical records. For nonchronically transfused patients, consent is renewed upon each patient admission. Furthermore, the policy requires that consent be obtained prior to a planned elective transfusion during the same admission period. Patients on long-term blood support (e.g. patients with underlying haemoglobinopathies and those undergoing chemotherapy) should provide consent annually with an option to withdraw their consent at any time during that period. In emergency situations where the patient or their guardian is unable or unavailable to provide consent, pre-transfusion consent requirements are waived; in these cases, patients or guardians are retroactively informed about the requirements of and reasons for performing the blood transfusion.

Prior to implementation of the policy, hospitalwide educational sessions were initiated to raise awareness of the new policy, procedures for transfusion consent, patient rights, the elements of consent, how consent is given and the validity of consent and its documentation. A pocket guide was made available and distributed to all nurses and physicians in the hospital to aid implementation of the policy. This study therefore aimed to assess adherence to the transfusion consent policy among different specialties at SQUH.

\section{Methods}

This cross-sectional retrospective quantitative study included all chronically and non-chronically transfused patients who underwent elective transfusions between June and August 2014. The medical records of these patients were examined for the presence of a transfusion consent form. In addition, the forms were examined for completeness of patient, physician and witness information and medical records were examined for any documentation of refusal of consent. Blood bank records of all blood components transfused during June-August 2014 were reviewed for information regarding issued blood components to ensure the inclusion of all patients during the study period.

Data collected were entered into Microsoft Excel, Version 2010 (Microsoft Corp., Redmond, Washington, USA) and analysed using the Statistical Package for 
Table 1: Characteristics of patients who underwent elective transfusions at the Sultan Qaboos University Hospital, Muscat, Oman, by admitting department* $(\mathrm{N}=446)$

$\begin{array}{lc}\text { Patient group } & \mathbf{n}(\mathbf{\%}) \\ \text { Adults }(\mathbf{n}=\mathbf{2 9 9}) & \\ \text { Haematology } & 149(50) \\ \text { Non-haematology } & 150(50) \\ \quad \text { Surgery } & 54(36) \\ \quad \text { Gynaecology and obstetrics } & 50(33) \\ \quad \text { Medicine } & 48(32) \\ \text { Paediatric (n = 147) } & \\ \text { Haematology } & 105(71) \\ \text { Non-haematology } & 42(29) \\ \quad \text { Neonatology } & 22(52) \\ \quad \text { General paediatrics } & 11(26) \\ \quad \text { Paediatric surgery } & 9(21)\end{array}$

"Assessed for the presence of transfusion consent in their clinical records.

the Social Sciences (SPSS), Version 22.0 (IBM Corp., Chicago, Illinois, USA). Descriptive statistics were used to summarise the results and associations were tested using Fisher's exact test. A $P$ value of $<0.0500$ was considered statistically significant.

Ethical approval for this study was obtained from the Medical Research \& Ethics Committee of the College of Medicine \& Health Sciences at Sultan Qaboos University (MREC \#961).

\section{Results}

During the study period, 446 transfused patients from different specialties were assessed, including 299 adult and 147 paediatric patients. Of these, $49 \%$ of the adult and $70 \%$ of the paediatric patients were on chronic transfusion support. Haematology patients accounted for $50 \%$ of adult patients, while the remaining adults were admitted by general medicine, surgery or obstetrics and gynaecology teams. The majority of transfused patients in the paediatric age group were haematology patients (71\%), with the rest admitted under the care of general paediatric, paediatric surgery and neonatology teams [Table 1].

Consent was obtained for a total of 359 subjects (75\% of adult and $91 \%$ of paediatric patients) [Table 2]. Paediatric and adult haematology specialists demonstrated the greatest adherence to the policy (97\% and $95 \%$, respectively). In contrast, only $55 \%$ of transfused patients under the care of adult nonhaematology services had documented transfusion consent forms. However, paediatric non-haematology
Table 2: Transfusion consent and degree of completeness of consent forms among patients who underwent elective transfusions at the Sultan Qaboos University Hospital, Muscat, Oman, by admitting department $(\mathrm{N}=446)$

\begin{tabular}{lcc} 
Patient group & \multicolumn{2}{c}{$\mathbf{n}(\%)$} \\
& Consent taken & $\begin{array}{c}\text { Completeness } \\
\text { of form }\end{array}$ \\
Adults $(\mathbf{n}=\mathbf{2 9 9})$ & $\mathbf{2 2 5}$ & $\mathbf{1 5 2}$ \\
Haematology & $142(95)$ & $114(77)$ \\
Non-haematology & $83(55)$ & $38(25)$ \\
Paediatrics (n = 147) & $\mathbf{1 3 4}$ & 76 \\
Haematology & $102(97)$ & $69(66)$ \\
Non-haematology & $32(76)$ & $7(17)$
\end{tabular}

specialists showed a higher adherence rate (76\%). Upon assessment of the completeness of the consent forms among paediatric patients, 52\% were filled out adequately with all of the required information. Adult and paediatric haematology specialists had correctly filled out consent forms in $77 \%$ and $66 \%$ of cases, respectively [Table 2].

A statistically significant difference was found between haematology and non-haematological specialists with regards to the completeness of consent forms for both adults and paediatric patients $(P=0.0001$ each). In both patient groups, the most common error was a lack of witness name and/or signature (20-25\%). In paediatric consent forms, $26 \%$ lacked the physicians' name in comparison to $13 \%$ of adult consent forms [Figure 1]. The names and signatures of the patients' parents or guardians were present in $95 \%$ and $97 \%$ of paediatric consents, respectively.

\section{Discussion}

Over recent years, patients have become more involved in their medical and surgical treatments. Despite

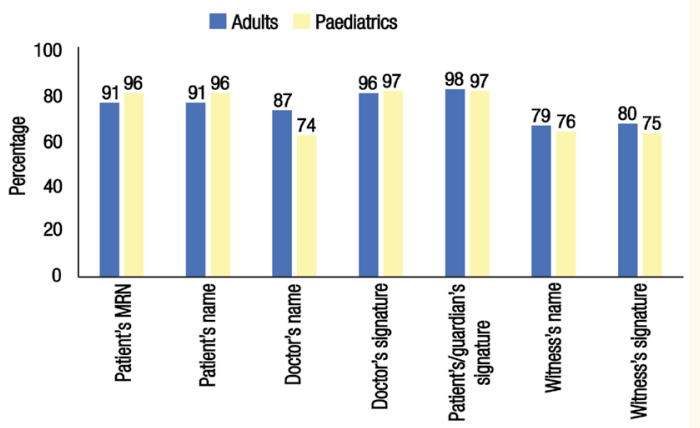

Figure 1: Chart showing the degree of completeness of various components of consent forms among patients who underwent elective transfusions at the Sultan Qaboos University Hospital, Muscat, Oman $(\mathrm{N}=359)$. $M R N=$ medical record number . 
this, inconsistencies have been reported in the practice of obtaining consent for blood transfusions. Transfusion consent has been mandated in some countries, while obtaining specific consent for a transfusion remains a novel concept in others. Furumaki et al. found that patients who were provided with information were more likely to have a better understanding of the risks and benefits of transfusion. ${ }^{13}$ However, research indicates that only $50-60 \%$ of transfusion patients recall having a discussion with their physicians or giving their consent for a blood transfusion; this indicates that current processes to aid informed patient decision-making fall short. ${ }^{7,9,14}$ Court et al. reported limited patient awareness of a transfusion having occurred at all, indicating a lack of communication between healthcare providers and their patients. ${ }^{7}$ In Oman, written patient consent for blood transfusions was not in practice at any government hospital before 2014 and SQUH was the first hospital in the country to implement a transfusion consent policy.

The findings of the current study show excellent adherence to the consent policy in the SQUH haematology specialty for both adult and paediatric cases. Further effort is hence required to enhance adherence in other specialties at SQUH. One explanation for the lower adherence to consent policy observed among non-haematology specialties in the current study could be a failure in documenting consent in medical records. Similar audits at other institutions have shown a lack of documentation of transfusion consent, raising the need for efforts to improve the documentation process..$^{15}$ At SQUH, the preliminary results of the current survey were presented to heads of departments and members of the blood transfusion committee; action plans were put in place for the reeducation of staff hospital-wide. In addition, a quarterly nursing-specific course on transfusion practices was initiated, with emphasis on aspects related to transfusion reactions and the consent process. An introductory session of transfusion policies in the hospital was prepared specifically for new physicians and residents. Moreover, re-assessment of policy adherence via a second survey is planned following the implementation of these remedial actions.

In addition, the findings of the present study have highlighted issues relating to the proper completion of transfusion consent forms. Lack of witness information was a common issue and the importance of this element should be emphasised in future policies. This finding may potentially be due to language or cultural barriers. It is important that the witness understands the language in which the consent explanation is given in order to be able to document consent properly.
In many healthcare settings, the witness is usually the nurse responsible for administering the blood components; at SQUH, the feasibility of this approach is limited as nurses do not always speak the same language as their patients. This problem is applicable to other aspects of the consent process as well and raises the need for specific hospital policies to address this issue.

Recently, the distribution of transfusion information pamphlets has been recommended as a means of improving information delivery, since patient rarely report being informed of the specifics of the transfusion or its benefits/risks. ${ }^{6,7}$ Nevertheless, it is important to note that these pamphlets cannot be given to illiterate patients or those with sight disabilities; furthermore, Court et al. found that although patients reportedly valued pamphlets as a source of information, over half of the patients who remembered discussing blood transfusions with their caregivers felt that the best source of information was a physician. ${ }^{7}$ Educational pamphlets were recently designed for distribution at SQUH in order to aid physicians during informed consent discussions. However, it was emphasised to the healthcare providers that written information should not replace verbal discussion with the patient during the consent process. Implementation of the consent process in other hospitals in Oman is advocated by the researchers as a vital step towards patient autonomy and to establish a method for the on-going monitoring of transfusion processes.

There is a lack of published data assessing the amount of information given to patients before obtaining transfusion consent or patients' levels of understanding of the information provided during the consent process. ${ }^{7}$ Informed consent for transfusion presumes that the patient has been given sufficient information, was able to comprehend the information provided and was given the opportunity to ask questions before making their decision. Furthermore, patients need to agree to undergo the intervention based on the information provided. In the current study, the degree of information provided or the patients' comprehension of the provided information was not assessed. Previous studies have shown that there is variability in the amount of information delivered to patients during the informed consent discussion. ${ }^{16,17}$ The current study lays the groundwork for further assessment of these aspects in the future.

Although blood transfusion consent policies have been applied in nearby countries as a result of accreditation requirements, to the best of the authors' knowledge, this study is the first from Oman to assess the degree of adherence to an informed consent policy. However, a few limitations of the study should 
be considered. First, the generalisability of this study may be limited since the subjects consisted of a patient cohort from a single institution. However, transfusion consent in Oman was only implemented at SQUH at the time of writing. The extent to which these findings can be replicated in a wider patient and physician population remains to be determined pending implementation of the policy at other hospitals. Second, the policy was introduced at SQUH relatively recently and it will thus understandably take further education of physicians and patients before a better level of adherence can be achieved. Third, the study assessed neither the degree of patient comprehension of information provided during the consent process, nor the details of what the physicians discussed with their patients. Further studies on these aspects are recommended.

\section{Conclusion}

This study describes the first experience of transfusion consent policy application in Oman and found high adherence among haematology specialties. Further effort is required to expand adherence in other medical and surgical specialties. Greater efforts should be made to provide information to patients about the benefits and risks of and alternatives to blood transfusion. Distribution of information pamphlets at SQUH is in process and will be followed by a second survey to assess the effectiveness of this in policy adherence. However, the adequacy of communication delivered and patient understanding during the consent process has yet to be assessed. The authors advocate implementation of the consent process in other hospitals in Oman as a vital step towards increased patient autonomy and to establish a method for ongoing monitoring of the transfusion process.

\section{CONFLICT OF INTEREST}

The authors declare no conflicts of interest.

\section{FUNDING}

No funding was received for this study.

\section{ACKNOWLEDGEMENTS}

This study was previously presented as a poster abstract at the American Association of Blood Banks (AABB) Annual Meeting in Anaheim, California, USA, on 24-27 October 2015. An abstract of the poster was published in Transfusion in 2015 (Vol. 55, Iss. S3, P. 166A).

\section{References}

1. World Health Organization. The clinical use of blood: Handbook. From: www.who.int/bloodsafety/clinical_use/en/ Handbook_EN.pdf Accessed: Mar 2016.

2. Williams FG. Consent for transfusion. BMJ 1997; 315:380-1. doi: 10.1136/bmj.315.7105.380.

3. Farrell AM, Brazier M. Consent for blood transfusion. BMJ 2010; 341:c4336. doi: 10.1136/bmj.c4336.

4. Holland PV. Consent for transfusion: Is it informed? Transfus Med Rev 1997; 11:274-85. doi: 10.1016/S0887-7963(97)80093-4.

5. Willett DE. The duty to warn about transfusion risks. Arch Pathol Lab Med 1989; 113:307-10.

6. Rock G, Berger R, Filion D, Touche D, Neurath D, Wells G, et al. Documenting a transfusion: How well is it done? Transfusion 2007; 47:568-72. doi: 10.1111/j.1537-2995.2007.01157.x.

7. Court EL, Robinson JA, Hocken DB. Informed consent and patient understanding of blood transfusion. Transfus Med 2011; 21:183-9. doi: 10.1111/j.1365-3148.2011.01069.x.

8. Capen K. There's more to Krever's report than the blood issue: Much more. CMAJ 1998; 158:92-4.

9. Davis R, Vincent C, Sud A, Noel S, Moss R, Asgheddi M, et al. Consent to transfusion: Patients' and healthcare professionals' attitudes towards the provision of blood transfusion information. Transfus Med 2012; 22:167-72. doi: 10.1111/j.1365-3148.2012.01148.x.

10. Eisenstaedt RS, Glanz K, Smith DG, Derstine T. Informed consent for blood transfusion: A regional hospital survey. Transfusion 1993; 33:558-61. doi: 10.1046/j.1537-2995.1993. 33793325050.x.

11. Wilkinson J, Wilkinson C. Administration of blood transfusions to adults in general hospital settings: A review of the literature. J Clin Nurs 2001; 10:161-70. doi: 10.1111/j.13652702.2001.00444.x.

12. Government of Canada. Final report: Commission of inquiry on the blood system in Canada. From: http://publications. gc.ca/site/eng/72717/publication.html Accessed: Mar 2016.

13. Furumaki $H$, Fujihara $H$, Yamada $C$, Watanabe $H$, Shibata $H$, Kaneko M, et al. Involvement of transfusion unit staff in the informed consent process. Transfus Apher Sci 2016; 54:150-7. doi: 10.1016/j.transci.2015.12.002

14. Chan T, Eckert K, Venesoen P, Leslie K, Chin-Yee I. Consenting to blood: What do patients remember? Transfus Med 2005; 15:461-6. doi: 10.1111/j.1365-3148.2005.00622.x.

15. Moog R. Lessons learned from transfusion audits. Transfus Apher Sci 2016; 54:377-9. doi: 10.1016/j.transci.2015.11.017.

16. Friedman M, Arja W, Batra R, Daniel S, Hoehn D, Paniz AM, et al. Informed consent for blood transfusion: What do medicine residents tell? What do patients understand? Am J Clin Pathol 2012; 138:559-65. doi: 10.1309/AJCP2TN5ODJLYGQR.

17. Cheung D, Lieberman L, Lin Y, Callum J. Consent for blood transfusion: Do patients understand the risks and benefits? Transfus Med 2014; 24:269-73. doi: 10.1111/tme.12141. 